\title{
CUENTOS FEOS \\ DE LA REFORMA AGRARIA PERUANA
}

\author{
Raúl Marcelo Doroteo \\ Universidad Nacional Mayor de San Marcos \\ cesarraulmado@gmail.com
}

"este libro [Cuentos feos de la reforma agraria] pretende hacer esto rememorando lo bueno, lo malo y lo feo a través de las narraciones de la gente que vivió en esos tiempos

[de la reforma agraria velasquista]"

El Instituto de Estudios Peruanos (IEP) presenta esta reedición de Cuentos feos de la reforma agraria de Enrique Mayer, texto que se ha convertido en un clásico de la antropología peruana y cuya lectura resulta obligatoria debido al contenido, la metodología y las técnicas empleadas para practicar la antropología en el Perú.

Lo revelador del libro es que Enrique

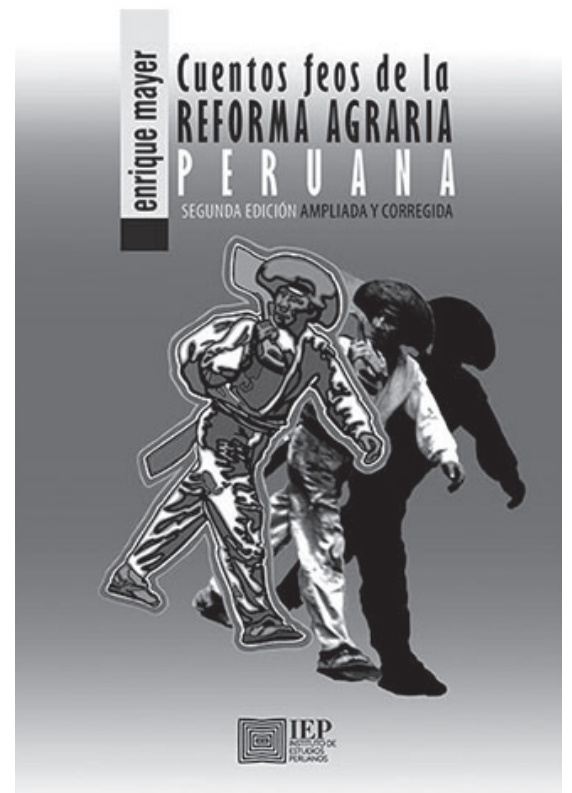
Mayer busca relatar la reforma agraria hilvanando los cuentos buenos, malos y feos de quienes experimentaron el proceso de la reforma agraria en el Perú acontecido durante las décadas de 1970 y 1980. Dichos cuentos son externalizados por los actores mediante las entrevistas realizadas por Enrique Mayer y Dany Pinedo. A partir de esta técnica, ambos antropólogos exploran la memoria de sus entrevistados, puesto que ella contiene toda la experiencia vivida en el momento histórico de la reforma agraria. El objetivo del texto no es discutir la historia de la reforma agraria, sino convertirse en "una invitación a los lectores a recordar y reflexionar, a contarse unos a otros más cuentos" de la época de la reforma agraria.

El texto está organizado en siete capítulos, cada uno con su respectiva conclusión. Cada capítulo, al estilo de una novela, presenta personajes con intereses, condiciones socioeconómicas y culturales diferentes. Las versiones resultantes son entrelazadas por Mayer -quien recurre muy poco a informaciones estadísticas, pues su análisis está basado principalmente en lo cualitativo- con el objetivo de elaborar una conclusión en cada capítulo. 
Mayer inicia el texto con un balance de lo que significó la reforma agraria para la sociedad peruana. No se inmiscuye en la discusión acerca de si fue un éxito o un fracaso, puesto que considera ese tema, bizantino e irrelevante. Sostiene que la reforma agraria velasquista es parte de un proceso histórico que transformó las estructuras tradicionales de la sociedad peruana, perjudicando a algunos y beneficiando a otros. Por tanto, lo que se debe discutir es cómo se llevaron a cabo los cambios cualitativos y cuál es, al presente, la realidad de los campesinos beneficiados o perjudicados por la reforma agraria.

La reforma agraria estuvo en la agenda de muchos líderes políticos liberales civiles, progresistas e incluso en la de los conservadores, así como fue una política internacional de los EE. UU. mediante la Alianza para el Progreso (ALPRO). La reforma agraria en el Perú fue impulsada timoratamente por la administración de F. Belaunde Terry. Ante ello, los militares progresistas liderados por Juan Velasco Alvarado tomaron el poder en 1968 e impulsaron la reforma agraria con el objeto de modernizar la agricultura y las zonas rurales, acabar con la oligarquía y los gamonales e incluir en el proyecto de nación a los campesinos pobres marginados. En suma, la reforma respondía a las necesidades de modernizar tanto el agro como al campesinado, pues se debía marchar en función al torbellino del capitalismo, que desvanece todo lo sólido que encuentra en su camino.

En este proceso de reforma agraria, los hacendados y la oligarquía fueron declarados enemigos del gobierno revolucionario. Sus versiones sobre la reforma agraria no fueron tomadas en cuenta por los académicos de las ciencias sociales que analizaron aquel proceso histórico; seguramente, también para ellos eran enemigos de clase. No obstante, Mayer ha recogido las versiones de todos los actores de la reforma. Por ello, los exhacendados, sus hijos y administradores tienen espacio para hablar y transmitir sus emociones en este texto, ya que muchos de ellos resultaron empobrecidos e, inclusive, lo perdieron todo. En sus memorias, se sienten estafados por el régimen velasquista, debido que el Estado no los indemnizó con el costo real de sus haciendas, sino que impuso arbitrariamente su cuantía. Pero también sucedió lo contrario: algunos hacendados se beneficiaron con aquel régimen, y estos fueron los Romero, quienes canjearon sus bonos agrarios con fines industriales.

Con las tierras expropiadas se constituyeron empresas asociativas. Este proyecto colectivista fue impulsado desde arriba, asesorado por intelectuales civiles de tendencia izquierdista, quienes lamentablemente no consideraron los deseos o las versiones de los campesinos acerca de la solución al problema de la tierra. En este proceso -en el cual el Estado fue el principal actor- lo que cambió fue el régimen de propiedad: se pasó de una privada a una asociativa o colectivista. Por consiguiente, la expropiación de tierras, lejos de promover la redistribución entre los campesinos, "consolidó la gran propiedad, la mayoría de las veces en unidades difíciles de manejar y territorialmente dispersas, que incorporaron dentro de sus fronteras una combinación de diversas formas de tenencia de la tierra y de sistemas de producción" (p. 185). Ese nuevo gran propietario fue el Estado, el cual reemplazó al hacendado. En teoría, las empresas asociativas fueron democráticas, pero en la práctica el Estado 
imponía sus prioridades (por ejemplo, fijar los precios de los productos agrarios, los cuales debían llegar a precios bajos al mercado urbano). Lo más paradójico fue que el Estado monopolizaba la compra-venta de las cosechas, pero se demoraba en girar los pagos a las empresas asociativas y éstas no podían pagar los intereses de las deudas contraídas con el Banco Agrario, de capital estatal. Las consecuencias de ello fueron los problemas de liquidez, descapitalización, endeudamientos y otros.

Para entender la complejidad de la empresa asociativa en la sierra, Mayer examina la manera en que se constituyó la empresa asociativa Tupac Amaru II, en la pampa de Anta, en Cuzco. La misma estuvo constituida por una población dispersa y diversa de 5.000 familias; "de ellas el 79 por ciento fueron miembros de comunidades campesinas que no formaron parte de la hacienda Sullupuquio, 10 por ciento sí formaron parte de las haciendas, 10 por ciento eran feudatarios y 2 por ciento todo tipo de personas" (p. 234). Esta diversidad de integrantes no fue tomada en cuenta por el Estado. Los integrantes de las comunidades campesinas no se sentían a gusto siendo parte de la empresa colectiva, puesto que se les negó el acceso directo a los pastizales y a las tierras agrarias, aunque ellos tenían la tradición de hacer producir la tierra o sus parcelas en privado; esta contradicción terminó sepultando a la empresa asociativa.

La comunidad campesina de Eqeqo Chocan fue integrada a la empresa Tupac Amaru II, pero estos comuneros habían recuperado sus tierras antes de la reforma agraria. Lamentablemente, con la reforma, sus tierras adjudicadas pasaron al control de la cooperativa. Y es que, para el Estado, la comunidad debía desaparecer con el proceso de la profundización de la reforma agraria. Pero esto no sucedió; por lo contrario, son las comunidades campesinas las que reformaron la reforma agraria velasquista: parcelaron las tierras e, incluso, se multiplicaron las comunidades campesinas. Los mismos campesinos tuvieron su propio programa de reforma agraria; para unir fuerzas, convocaron a un congreso nacional en 1978, promovido por la Confederación Campesina del Perú (CCP), siendo la anfitriona la comunidad campesina de Eqeqo Chocan, en Cuzco. Allí fueron acordadas las tomas de tierras y de carreteras para presionar al Estado buscando que acepte que ellos deben ser los reformadores.

Las empresas asociativas costeras y serranas entraron en crisis por problemas de corrupción, clientelismo, ineficiencia administrativa, exceso de personal, purgas entre los asociados por el control administrativo y pugnas entre socios y trabajadores eventuales. En la sierra, los comuneros creían ser los beneficiados directos de las tierras expropiadas a los hacendados; lo mismo sostienen los feudatarios, exyanaconas. En estas pugnas, también aparece el poder omnipotente del Estado, en calidad de patrón. Estas contradicciones darán paso a un nuevo proceso de parcelación de las tierras en unidades familiares y de regreso a la gran propiedad.

La estocada final a la reforma velasquista la dio el régimen fujimorista con sus medidas neoliberales en la década de 1990. De ese modo, acaece un regreso a la gran propiedad neolatifundista (por ejemplo, el Grupo Gloria cuenta con más de 60.000 hectáreas: Cartavio, Laredo, Casa Grande, San Jacinto; y los Oviedo, con Pomalca, Cayaltí y Tuman). 
A fin de cuentas, lo que nos trajo la reforma agraria fue la ampliación del espectro político de la sociedad peruana, donde ahora cabe el campesino como actor político, y muchos líderes campesinos se convirtieron en alcaldes de sus respectivos municipios distritales y provinciales. A la vez, convirtió a los campesinos en pequeños y medianos productores, que hoy luchan "contra las condiciones adversas del mercado, contra la competencia local y extranjera, y con la falta de capital". Pero la reforma no resolvió la pobreza extrema de los pobladores rurales ni ofreció alternativas para hacer frente a la gran explosión demográfica. 